\title{
FALLS BY ELDERS WITH MODERATE LEVELS OF MOVEMENT FUNCTIONALITY
}

\author{
Marise Akemi Ishizuka, Eduardo Gennaro Mutarelli, Angélica Massako Yamaguchi \\ and Wilson Jacob Filho
}

ISHIZUKA MA et al. Falls by elders with moderate levels of movement functionality. CLINICS 60(1):41-46, 2005.

PURPOSE: To trace the socio-functional and clinical profiles of elders with moderate levels of movement functionality as determined by the Performance-Oriented Mobility Assessment (POMA Ia), and to compare the groups having high and moderate levels of functionality regarding the frequency of falls and identifiable risk factors.

METHODS: The research involved 49 elders (with an average age of 71.24, SD 5.47) who were seeking medical care in the geriatric unit of a tertiary care hospital. Study participants were evaluated regarding their balance and gait (POMA Ia assessment), muscle strength (chair-stand test), gait velocity (timed up and go test), incidence of falls, and other clinical risk factors.

RESULTS: The moderate functionality group reported significantly more falls (14) compared with the high functionality group (3). Of the risk factors evaluated, the presence of depression or of a psychiatric record was significantly more frequent in the moderate-functionality group but was not correlated with an increase in falls., Muscle weakness was found significantly more frequently in the moderate-functionality group and was significantly correlated with an increased frequency of falls.

CONCLUSIONS: These findings suggest that the POMA Ia assessment can identify individuals with an increased risk of falling, and the treatment of risk factors such as depression or a psychiatric record, and muscle weakness could help prevent the occurrence of falls in elders with moderate functionality as determined by the POMA Ia assessment.

KEYWORDS: Elders. Assessment. Functional tests. Balance. Gait. Falls.

A number of studies have presented data about some of the risk factors and the frequency of falls ${ }^{1,4,10,11}$. However, questions about different profiles of subjects who fall and the factors that contribute to the occurrence of falls demand further research. The classic division of the elderly into 2 groups, subjects that fall and do not fall, presents a certain weakness with regard to the evaluation due to the multifarious nature of the falls in the studies.

One of the few studies that researched groups with different functional characteristics and the relationship with falls was done by Speechley and Tinetti, ${ }^{1}$ where the elders were divided into 3 groups: vigorous, transitional, and frail according to their score in an 18-item questionnaire about

From Hospital das Clínicas, Faculty of Medicine, University of São Paulo, São Paulo/SP, Brazil.

E-mail: mariseishizuka@yahoo.com.br

Received for publication on July 30, 2004.

Accepted for publication on October 15, 2004. demographic, physical, and psychological characteristics. The frail elders group experienced a high percentage of falls during the year of the research. When compared with falls among the frail group, the vigorous group experienced falls resulting in more serious injuries. The falls of vigorous elders tended to be on stairs and away from home, probably consequent to doing risky tasks with more exposed behavior.

In many of the studies that correlate performance with functional tests of balance and gait with risk of falls, the relationship between level of functionality and incidence of falling was not a simple linear one. Although vigorous active elders have been found to fall less frequently than less active ones, their falls result in more serious injuries because, it is thought, they expose themselves to risky situations, whereas elders with functional deficits are more careful because they respect their limitations. ${ }^{1}$ The elderly popu- 
lation in transition from vigorous to frail has been shown to fall less frequently than the frail elderly population, but these individuals must certainly be undergoing changes that may result in a higher frequency of falls as they age.

Our goal in this study was to determine among elders having functionality that is intermediate between vigorous and frail whether there are identifiable factors predisposing individuals to a greater risk of falling that could be responsive to preventative measures.

\section{SUBJECTS}

The study population was 49 volunteers who were seeking medical care in the geriatric service of a tertiary hospital. These elders had never been attended by geriatric specialists before; they were referred by outside doctors or other specialists to the service.

The elders who participated in this research were screened according to the following criteria:

- Willingness to accept an intervention and sign the consent form to participate in the research;

- Age over 60 years;

- Ability to walk at least 6 meters without any support from other people;

- Absence of significant mobility deficit (PerformanceOriented Mobility Assessment — POMA IA — less than $25)$;

- Absence of cognitive deficits that might inhibit the ability to answer the questionnaires.

\section{METHODS}

Data collection instruments:

- Personal profiles with patient information to facilitate contact; basic information about the activities of daily living-ADLs; ${ }^{2}$ instrumental activities of daily livingIADLs; ${ }^{3}$ usual medicines.

- Performance-Oriented Mobility Assessment-POMA IA, ${ }^{4}$ which includes 2 evaluations related to balance and gait:

- Performance-Oriented Assessment of Balance. This evaluation scores the performance of the patient doing 13 activities that reproduce daily routine movements that require balance. The score is given on the elder's performance for each task. The grades are from 0 to 2 , where the lowest grade means that the patient cannot do the activity and the highest grade represents a target performance. The highest grade in this evaluation is 26 points.

- Performance-Oriented Assessment of Gait. In this gait evaluation, 9 items are observed: (i) beginning of the gait, height, length, width, symmetry, (ii) during the gait; deflection of the trajectory; stability of the trunk, and returning while you walk. The patient is asked to walk 6 meters in regular steps. Each item is scored from 0 to 1 where zero is considered unsatisfactory performance and 1 a normal performance. The highest score in this evaluation is 9 points.

The results of the two evaluations are added to obtain the final score.

- Timed up and go test. ${ }^{5}$ The test evaluates the velocity of the patient during the task of standing up from the chair, walking 3 meters, coming back and sitting down. The velocity in which the patient executes the test is related to his/her risk of fall. A total time of less than 20 seconds indicates the patient has a small risk of falling, between 20 and 30 seconds a moderate risk, and more than 30 seconds a high risk of falling. This test was elaborated and adapted from the get up and go test. 6

- $\quad 30$-s chair-stand test. ${ }^{7}$ The test evaluates the strength of inferior limbs through the number of repetitions of standing up from a chair in 30 seconds.

- A protocol of falls. An evaluation protocol developed by the geriatrician and the neurologist of the Prevention of Falls Clinic, to collect data about the risks of falls in evaluated elders. The definition of fall adopted in this study was any event that results in an unexpected contact with the ground, support area, wall, or objects; this contact can be by any part of the body except the superior limbs. Trips, slips, automobile accidents or large external impacts impossible to avoid were excluded.

Participants were interviewed and evaluated by a physical therapist, with the goal to detect risk factors, compile a history of falls as reported by patients and/or family members, and collect the personal medical files.

Subsequently, participants were also evaluated by a geriatrician to obtain the clinical risks (personal profiles) of falls. The patient received orientation about risks of falling and changes in medicines if necessary. The neurologist evaluated only the cases referred by geriatrician.

Based on their scores on the POMA Ia assessment, participants were classified into 2 groups: moderate and high functionality. Scores over 33 points were classified as high functionality, scores of 25 to 32 , they were classified as moderate functionality. This rating table was devised by the authors.

Statistical analysis was performed using S.A.S. (Statistical Analysis System). Data were tabulated and entered in the program for descriptive and exploratory summaries (frequency, averages, standard deviation) and for analysis of associations among the variables ( $t$ test, chi-square test). Statistical significance was declared when $P<.05$. 


\section{RESULTS}

According to their scores on the POMA IA test, participants were divided into the two risk groups as follows: moderate $(\mathrm{n}=27 ; 55 \%)$ and high functionality $(\mathrm{n}=22$; $45 \%)$. These two groups were then analyzed and compared with regard to frequency of falls. The moderate-functionality group experienced significantly $(P=.0052)$ more falls than the high-functionality group (Table 1 ).

Regarding personal profile information, notable findings for the sample overall were as follows: (i) $94.1 \%$ of the patients who fell were women, (ii) the high-functionality group had no subject over 75 years of age (Table 2), and (iii) the average age in the moderate-functionality group was significantly greater $(P=0.0353)$ than in the high-functionality group (Table 3 ).

As regards the 30-s chair-stand and the timed up and go tests, the high-functionality group scored significantly higher $(P=0.0353)$ on the 30 -s chair-stand test (Table 3$)$.

Regarding IADLs, the moderate-functionality group had significantly $(P=.0241)$ more dependency in at least

Table 1 - Relationship between the functionality level and falls.

\begin{tabular}{lcrcc}
\hline \multirow{2}{*}{$\begin{array}{l}\text { Functionality } \\
\text { Level }\end{array}$} & \multicolumn{2}{c}{ Fell down } & Total & Chi-square \\
\hline Moderate & 13 & 14 & 27 & 0.0052 \\
High & 19 & 3 & 22 & \\
Total & 32 & 17 & 49 & \\
\hline
\end{tabular}

one of the activities (Table 4). There was no difference between groups regarding the level of physical activity.

From the diseases identifiable through the medical interview, only depression, a psychiatric record, or muscle weakness produced some association between the groups. There were significantly $(P=.0016)$, more reports of depression or a psychiatric record in the moderate-functionality group; however, there was not a significant association between depression the frequency of falls. Regarding muscle weakness, there was a significantly $(P=.0284)$ increased frequency in the moderate-functionality group, and there were significantly $(P=.0013)$ more falls experienced by the individuals having muscle weakness.

\section{DISCUSSION}

Subjects in this study were generally typical of elderly people seeking public medical services and of the Brazilian population in this age group, in that they had little schooling and were mostly inactive.

When study participants were divided into 2 groups based on the POMA test, the moderate-functionality group reported significantly more falls. A moderate-functionality group is not usually the subject of studies of falls. In most studies, the groups are split into high- and low-functionality groups or by occurrence or not of falls. The results of such research indicate that even though the studies about falls do not stratify elders into moderate levels of functionality, there is a difference in risk of falling among the elders who are not in the low-functionality category.

Table 2 - Distribution of personal profile parameters (\%).

\begin{tabular}{|c|c|c|c|c|c|c|}
\hline & & Total group & $\begin{array}{c}\text { Moderate } \\
\text { functionality } \\
\text { group }\end{array}$ & $\begin{array}{c}\text { High } \\
\text { functionality } \\
\text { group }\end{array}$ & $\begin{array}{l}\text { Experienced } \\
\text { falls }\end{array}$ & $\begin{array}{l}\text { Without } \\
\text { falls }\end{array}$ \\
\hline \multirow[t]{2}{*}{ GENDER } & Women & 73.47 & 81.5 & 63.6 & 94.1 & 62.5 \\
\hline & Men & 26.53 & 18.5 & 36.4 & 5.9 & 37.5 \\
\hline \multirow[t]{5}{*}{ AGE GROUP } & d"65 years & 20.41 & 18.5 & 22.7 & 29.4 & 15.6 \\
\hline & From 66 to 70 years & 26.53 & 25.9 & 27.3 & 17.6 & 31.2 \\
\hline & From 71 to 75 years & 34.69 & 22.2 & 50 & 23.5 & 40.6 \\
\hline & From 76 to 80 years & 12.24 & 22.2 & 0 & 23.5 & 6.2 \\
\hline & Over than 80 years & 6.12 & 11.1 & 0 & 5.9 & 6.2 \\
\hline \multirow[t]{4}{*}{ MARITALSTATUS } & Married & 63.27 & 63 & 63.6 & 52.9 & 68.8 \\
\hline & Divorced & 6.12 & 7.4 & 4.5 & 11.8 & 3.1 \\
\hline & Single & 6.12 & 0 & 13.6 & 0 & 9.4 \\
\hline & Widow & 24.49 & 29.6 & 18.2 & 35.3 & 18.8 \\
\hline \multirow[t]{5}{*}{ SCHOOLING } & Illiterate & 10.20 & 11.1 & 9.1 & 17.6 & 6.2 \\
\hline & Literate & 10.20 & 18.5 & 0 & 17.6 & 6.2 \\
\hline & Elementary & 63.27 & 63 & 63.6 & 52.9 & 68.8 \\
\hline & High school & 12.24 & 7.4 & 18.2 & 5.9 & 15.6 \\
\hline & College & 4.08 & 0 & 9.1 & 5.9 & 3.1 \\
\hline \multirow[t]{2}{*}{ PHYSICAL ACTIVITY } & Sedentary & 75.51 & 81.5 & 68.2 & 76.5 & 75.0 \\
\hline & Active & 24.49 & 18.5 & 31.8 & 23.5 & 25.0 \\
\hline
\end{tabular}


Table 3 - Average, standard deviation, and chi-square of the variables: age, number of the diseases, number of medicines, timed up and go test, and repetitions in the 30-s chair-stand test in relationship to the functionality group and total group.

\begin{tabular}{|c|c|c|c|c|}
\hline Variable & Moderate functionality & High functionality & Total & Chi-square \\
\hline Age & $72.85(6.22)$ & $69.27(3.63)$ & $71.24(5.47)$ & 0.0158 \\
\hline Number of diseases & $9.81(4.79)$ & $8.23(3.32)$ & $9.10(4.23)$ & 0.1942 \\
\hline Number of medicines & $3.85(2.10)$ & $2.86(2.27)$ & $3.40(2.21)$ & 0.1217 \\
\hline Timed up and go test & $12.04(2.82)$ & $11.00(1.88)$ & $11.57(2.47)$ & 0.1464 \\
\hline 30 -s chair-stand test & $9.81(2.71)$ & $11.68(3.31)$ & $10.65(3.11)$ & 0.0353 \\
\hline
\end{tabular}

Table 4 - Relationship of functionality group to the instrumental activities of daily living (IADL) and physical activity.

\begin{tabular}{|c|c|c|c|}
\hline \multirow[t]{2}{*}{ IADL score } & \multicolumn{2}{|c|}{ Functionality Group } & \multirow[t]{2}{*}{ Chi-square } \\
\hline & Moderate & High & \\
\hline Less than 8 & 8 & 1 & 0.0241 \\
\hline 8 or more & 19 & 21 & \\
\hline Physical activityActive & 5 & 7 & 0.2816 \\
\hline Sedentary & 22 & 15 & \\
\hline
\end{tabular}

Regarding the age factor, we found that increased age was significantly correlated with decreased functionality, and no one over 75 years of age was classified as having high functionality. However, age was not found to be related to the frequency of falls.

A clear cut finding in our study was that a large majority of falls were experienced by women, which corresponds to other published reports that show that being a female is an important risk factor for falls. ${ }^{8}$

Regarding the number of related diseases, the participants presented an average of 9.1 diseases. This number is considered high, but it should be remembered that study participants were selected from a population of patients seeking medical care

The average number of medicines consumed by all the subjects was also high, and polypharmacy has been reported to be a risk factor for falls. ${ }^{8,11}$ The number of medications indicates the number of co morbidities the person has. In this study, however, there was no significant correlation between the number of comorbidities and the number of medications taken and functionality in our study. Dependency in the IADLs has been related primarily to fragility and secondarily to adaptation to the environment. ${ }^{9}$ In our study, all the elders presented independence for ADLs and $16.4 \%$ of the elders presented dependency at least one in IADL. There was a significant correlation between the occurrence of dependency in an IADL and being classified into the moderate-functionality group. These data indicate, by criteria of inclusion of this research, that the participating elders were independent in activities of daily life, and only in the assessment for IADLs did we find some dependency. The elders in the moderate functionality group were more dependent compared to those in the high functionality group.

In the functional tests, the study data were interesting because regarding the velocity in the timed up and go test, all the subjects presented a low risk for falls according to the standard of the authors who developed to the test. ${ }^{5}$ When our results were analyzed by functionality group, there were no significant differences regarding this test.

Some reports indicate that depression or the medications for depression is associated with a decrease in reflex speed and alertness. ${ }^{8,10}$ Those studies indicate that depression is associated with reduced performance in balance and gait tests and thus can increase the risk of falls. However, in our study, although patients who showed indications of depression were more likely to be classified into the moderatefunctionality group, they were not more likely to fall.

Many studies indicate an association between weakness and falls in elders. Paschoal reported that weakness was the second major reason for falls, with the disturbance of balance and gait being first. ${ }^{11}$ In our study, the average score for all participants in 30-s chair-stand test was lower than

Table 5 - Frequency and chi-square of pathology: depression and antecedents and muscle weakness in relation to the functionality group and incidence of falls.

\begin{tabular}{|c|c|c|c|c|c|c|c|}
\hline \multirow[t]{2}{*}{ Pathology } & & \multicolumn{3}{|c|}{ Functionality Group } & \multicolumn{3}{|c|}{ Fall-related } \\
\hline & & Moderate & High & Chi-square & Fell down & $\begin{array}{l}\text { Without } \\
\text { falls }\end{array}$ & Chi-square \\
\hline \multirow[t]{2}{*}{ Depression and psychiatric antecendents } & Yes & 17 & 4 & 0.0016 & 9 & 12 & 0.2985 \\
\hline & No & 10 & 18 & & 8 & 20 & \\
\hline \multirow[t]{2}{*}{ Muscle weakness } & Yes & 13 & 4 & 0.0284 & 11 & 6 & 0.0013 \\
\hline & No & 14 & 18 & & 6 & 26 & \\
\hline
\end{tabular}


is considered normal for the average of age for both genders according to the norms established by the author of the test. ${ }^{7}$ However, those in the high-functionality group were able to complete more repetitions on average than those in the moderate-functionality group. And among elders who had experienced falls, the frequency of muscle weakness was significantly higher than among those who had not experienced falls.

In summary, the most common profile of the moderatefunctionality group was that of a married sedentary female with a basic level of schooling and having a large number of co morbidities and polypharmacy. This profile differed from that of the high-functionality group in that moderate functionality participants were older, had a greater frequency of depression, and more muscle weakness.

Elders having moderate levels of movement functionality are important targets in the efforts to prevent falls because of the natural tendency of this population to start to decline and join the low-functionality category - a group with a substantially increased risk of falling-indicating the necessity for more studies regarding this risk group. Explorations in the treatment of the risk factors such as muscle weakness and depression could contribute to the prevention of falls in elders having moderate levels of functionality. The POMA Ia assessment may be useful in identifying individuals who are at greater risk of falling and who may have preventable risk factors.

\section{RESUMO}

ISHIZUKA MA e col. Quedas em idosos: grupo de risco moderado. CLINICS 60(1):41-46, 2005.

OBJETIVO: Traçar o perfil sócio-funcional e clínico de idosos com risco moderado de quedas e compará-lo com idosos de baixo risco, identificando os fatores avaliados que correlacionassem com o risco e o relato de queda.

MÉTODOS: O estudo avaliou 49 idosos (com média de idade de 71,24 anos, DP 5,47) que procuraram atendimento num ambulatório de triagem geriátrica de um hospital de nível terciário. Foram avaliados: equilíbrio, marcha (avaliados pelo teste POMA Ia), força muscular (30's chair stand), velocidade da marcha (timed up and go), incidência de quedas e outros riscos clínicos.

RESULTADOS: O grupo de risco moderado relatou mais quedas (14 idosos) do que o baixo risco (3), atingindo a significância estatística $\left(\chi^{2}=0,0052\right)$. Dentre os fatores de risco avaliados a presença de depressão ou antecedentes psiquiátricos foi mais freqüente no risco moderado $\left(\chi^{2}=\right.$ 0,0016), porém, não apresentou diferença quando a variável era o relato prévio de quedas. A presença de fraqueza muscular apresentou associação estatística tanto em relação ao risco $\left(\chi^{\mathrm{C} 2}=0,0284\right)$ quanto à queda $\left(\chi^{2}=0,0013\right)$.

CONCLUSÃO: Estes dados sugerem que o POMA Ia é um instrumento para a identificação de pacientes com risco de quedas e que fatores como depressão ou antecedentes e fraqueza muscular estão associados a ocorrência de quedas em idosos de risco moderado.

UNITERMOS: Idosos. Avaliação. Testes funcionais. Equilíbrio. Marcha. Quedas.

\section{REFERENCES}

1. Speechley M, Tinetti M. Falls and injuries in frail and vigorous community elderly persons. J Am Geriatr Soc 1991;39:46-52.

2. Katz S, Ford AB, Moskowitz RW. Studies of illness in the aged: the index of ADL. JAMA 1963;185:914-9.

3. Lawton MP, Brody EM Assessment of older people: self-maintaining and instrumental activities of daily living. Gerontologist 1969;9:179-86.
4. Tinetti ME. Performance-oriented assessment of mobility problems in elderly patients. J Am Geriatr Soc 1986;34:114-26.

5. Podsiadlo D, Richardson S. The timed "up and go": a test of basic functional mobility for frail elderly people. J Am Geriatr Soc 1991:39:142-8

6. Matias S, Nayak UL, Isaacks B. Balance in elderly patients: the "get-up and go" test. Arch Phys Med Rehabil 1986;67:387-9. 
7. Jones CJ, Rickli RE, Beam WC. A 30-s chair-stand test as a measure of lower body strength in community-residing older adults. Research Quarterly for Exercise and Sport 1999; 70(2);113-119.

8. Nevitt MC. Falls in the elderly: Risk factors and prevention. In: Masdeu, JC, Sudarky L, Wolfson L. Gait disorder of agingfalls and therapeutic strategies. Lippincott-Raven Publishers, Philadelphia, 1997;13-36.

9. Peña-Casanova J. Escalas funcionales e instrumentales de las actividades de la vida diaria. Revista de Neurologia 1998;27:S27S29.
10. Moura RN, Santos FC, Driemeier M, Santos LM, Ramos LR. Quedas em idosos: fatores de risco associados. Gerontologia 1999;7:1521.

11. Paschoal S. Como reduzir quedas no idoso. In: JACOB FILHO, W. Promoção da saúde do idoso. Lemos Editoria FMUSP, São Paulo, 1998; 65-75. 